ON CAMPUS

\title{
Experiential Education Conference at Stellenbosch University, South Africa, 10-11 November 2020
}

Ruth Andrews*

\section{Experiential Education as Pedagogy for Social Justice, Praxis and Practice for Shaping 21st-Century Global Citizen Leaders}

Stellenbosch University's Division Student Affairs, Centre for Student Leadership, Experiential Education and Citizenship's Co-curriculum Office, presented the Stellenbosch University Experiential Education Conference (SUEEC) from 10 to 11 November 2020. This was Stellenbosch University's first online conference and a first in South Africa and Africa focusing on experiential education and social justice. This two-day virtual higher education conference was collaboratively designed with experiential educators in civil society, university student affairs practitioners, and academics from across the world.

The conference theme of 'Experiential education as pedagogy for social justice: praxis and practice for shaping 21st century global citizen leaders' emerged even more pertinent at a time of mass global upheaval, uncertainty and humanitarian crises. The intention of the SUEEC was to spotlight emerging trends and transitions in the higher education experiential learning domain and the intersections thereof with social justice and the formation of the global citizen leader. To accomplish the above entailed inviting world renown keynote speakers and subject matter experts, and to call for abstracts, master classes and exemplars (examples of best practice in experiential education).

The conference was designed for higher education experiential educators, student affairs practitioners, university academics, researchers, social justice educators and practitioners, and all who are interested in embedding social justice frameworks within higher education experiential learning opportunities. The SUEEC offered a unique opportunity to contribute to and engage with diverse views and collective envisioning of shaping pathways for transformative teaching and learning. A total of 221 participants attended the SUEEC, representing 40 institutions from 14 countries: Germany, United Arab Emirates, Kenya, Namibia, Nigeria, Ghana, Philippines, United States of America, Singapore, Spain, United Kingdom, Turkey, Hawaii and South Africa.

The SUEEC invited experiential educators to explore the notion of Experiential Education as Pedagogy for Social Justice through the lenses of the five Conference tracks: Experiential Education and Student Transformation; Emerging Social Justice Frameworks

* Ruth Andrews is an Experiential Educator and heads the experiential learning project in the Centre for Student Leadership Experiential Education and Citizenship at Stellenbosch University, South Africa.

Email: rutha@sun.ac.za 
in Higher Education; Global Citizen Leadership; Internationalisation in Higher Education, and Research and Innovation in Experiential Education.

The SUEEC was designed as an experiential learning journey integrating participant engagement, exemplars of best practice, keynote addresses and master classes, as well as a research focus through virtual paper presentations. The SUEEC's design was theoretically grounded in the work of Dewey and David Kolb, and drew on Paulo Freire's pedagogy of social justice, which states that learning as transformation carries the potential to become a mechanism for affecting social justice.

Reflecting the understanding that experiential learning is a philosophy rather than a methodology, the SUEEC emphasis was on exploring experiential learning as lived reality in various contexts from across the world. The two-day experiential learning journey was mapped to a praxis element led by Alice Kolb and a practice element led by George Kuh. Therefore, Day 1 focused on the Praxis of experiential learning and the various discourses surrounding experiential learning as a philosophy, as well as on how this finds expression in various contexts. Day 2 focused on the Practice of experiential learning and what is being done and needs to be done to realise the transformative power of experiential education towards creating a more equitable society. The SUEEC offered two online modalities: video-streaming of pre-recorded content, and live-streaming of live-recorded engagement.

Participants had the following to say about the design:

I appreciated the distinction between day 1 and day 2 in terms of the reflecting/reconnecting on day 1 and on day 2 revisioning/repositioning and recalibrating. Having had some time to reflect on the 2 days, I can truly say my experience resonates with these descriptors.

The following highlights made SUEEC an extraordinary event in extraordinary times as expressed by participant feedback below.

The themes for SUEEC Day 1 was Reflecting and Reconnecting and the opening conference sequence featured the world renowned Stellenbosch University Choir and a warm welcome by the rector, Prof. Wim de Villiers.

Keynote 1: Alice Kolb in Panel Conversation, together with an inter-generational panel of experiential educators, unpacked the six principles of experiential learning. This session was foundational to the understanding of experiential learning as a philosophy and set the tone for the day in terms of exploring the praxis of experiential education.

I found Keynote \#1 Experiential Education and Transformative Learning: Principles and Practices -

Prof. Kolb in Panel Conversation to be exceptionally thought-provoking as it included students, staff and experts. Was really engaging and enlightening.

The SUEEC showcased experiential education exemplars that demonstrated the SUEEC conference tracks. The exemplars presented an opportunity to experiential educators to share examples of experiential learning best practice that have led to transformative learning in institutions.

The exemplars were an informative experience. I never heard about the name of such a method. So I learned how to call them and also the examples were so relevant to give the participants a deeper insight. 
Keynote 2: Thuli Madonsela and Choice Makhetha in Conversation addressed the issue of social justice frameworks in higher education. The keynote speakers focused on student activism and how this finds expression in higher education such as gender-based violence, racism and issues of access and redress.

The most helpful are Experiential Education and Transformative Learning, as well as Emerging Social Justice Frameworks in Higher Education. The first two rendered me an opportunity to learn new things.

Conference participants had the opportunity to attend two master classes to develop skills and capabilities towards designing transformative experiential learning opportunities. The master classes provided interactive engagement, deep learning and reflexivity.

Master Class 1 led by Mustafa Erdogan focused on the praxis of experiential learning as pedagogy for social justice. Erdogan drew on case studies to illustrate how the experiential educator's world view influences the praxis and practice of experiential learning. The work of Paulo Freire formed the framework of integrating experiential learning and social justice in the design and development of experiential learning processes.

Mr Mustafa Erdogan's Master class really gave a grounded approach to experiential learning.

The conference themes for Day 2 were Revisioning, Repositioning and Recalibrating. The highlights of SUEEC Day 2 were as follows:

Keynotes 3 \& 4: Jonathan Jansen and Hester Klopper approached the topic of Internationalisation in higher education from two distinct vantage points of social justice and transformation, with Klopper viewing the topic from the SU institutional perspective. The participants' views of their experiential learning are reflected below:

Prof Jansen's session on 'Internationalisation in Higher Education: A view through the social justice lens'. This session was meaningful to me as Prof Jansen covered pertinent societal challenges that speak to the African and South African context.

Prof Hester Klopper's session outlined the challenges we face and what higher education and our students could gain from incorporating experiential training within higher education.

SUEEC Day 2 provided participants an opportunity to attend virtual paper presentations that focused on the five conference tracks. Selected abstracts were double-blind peer reviewed by an abstract review panel. Authors were granted the opportunity to amend their virtual submissions based on feedback before final submission of a video-streamed paper presentation. A total of 20 presenters with 11 virtual papers covering the five conference tracks showcased their research efforts in the area of experiential education. For many researchers, it was a 'first' in terms of presenting a virtual paper and engaging in a livestreamed Q\&A session.

Keynote 5: George Kuh and Arnold Schoonwinkel were undoubtedly the highlight for many of the participants as they presented synthesis of the experiential learning journey. This is what participants had to say about the session:

Schoonwinkel and Kuh - seasoned teachers - excellent presentation, insightful, detailed, relevant, learnt a lot. 
This session made me aware that if we the curriculum designers and developers are on the same page and have the same shared understanding, it would be smoother to change the curricula in every field to consider the required experiential exposure for each field or career.

SUEEC Master Class 2 led by Kuh demonstrated the power and efficacy of impact practices and precisely how and why these work. Kuh presented participants with valuable evidenced-based learnings and techniques that could be applied in various learning contexts. The research and innovation track was demonstrated when Kuh shared new research on peer-to-peer learning.

Last Master class, I learnt a lot of relevant information; the session from Prof. Kuh was excellent.

Both masterclasses were superb!! They encouraged critical thinking and offered so many useful practical strategies.

Keynotes 3 \& 4 shared a joint moderated Q\&A session, while Keynote 5 and Master Class 2 shared a Q\&A session. Both sessions were well received with high levels of engagement, and the diversity of thinking and experience was appreciated by the participants.

The primary focus of the final session, led by Kay Peterson from the Institute for Experiential Learning (USA), was to begin the conversation on starting an intercontinental community of practice. The date for the first conversation is set for 10 December 2020 .

The conference proceedings drew to a close on Day 2, beginning a new experiential learning journey, continuing the work in the form of an experiential learning community of practice. We look forward to reporting on this new experiential learning chapter in the near future. Participant feedback in the form of appreciation and reflections of experiential learning are clear indicators of a conference that achieved its purpose and objectives.

I will integrate the Master Class materials in my daily practices and I will review my praxis of experiential learning.

I will add some of the tips to my facilitation toolkit.

I have been challenged to think differently about my role as an educator and the power dynamics at play.

First, I am in charge of Faculty Affairs and responsible of Lecturer Professional Development in my University and hence I will consider ways to train more lecturers to be able to incorporate experiential learning practices in their courses.

I am going to integrate my SUEEC experiential journey in my professional journey through the review of program units and more specifically, the learning outcomes, mode of delivery and student activities.

I will think more critically about Kolb's Learning Styles and Experiential Learning Cycle and Kuh's High Impact Activities.

\section{How to cite:}

Andrews, R. 2020. Experiential Education Conference at Stellenbosch University, South Africa, 10-11 November 2020. Journal of Student Affairs in Africa, 8(2), 137-140. DOI: 10.24085/jsaa. v8i2.4453 